\title{
Fuzzy logic in competence management
}

\author{
Raymond Houé ${ }^{1}$, Bernard Grabot ${ }^{1}$, Germaine Tchuente ${ }^{1}$ \\ ${ }^{1}$ Université de Toulouse, INPT, LGP-ENIT \\ 47, avenue d'Azereix, BP 1629 \\ F-65016 Tarbes, France
}

\begin{abstract}
Industrial performance has for a long time been considered as a result of technical resources optimization. During the recent decades, competencybased approach has emerged as a promising concept for taking into account human skills/knowledge/abilities while addressing organizational goals and constraints. The aim for the companies is for instance to assess the compliance of competences acquired by workers with those required by the processes in which they are involved. In order to achieve this general purpose, it becomes necessary to provide the companies with an operational DSS capable of assessing competences. This paper focuses on a fuzzy based approach for modelling the competences in such a system.
\end{abstract}

Keywords: competence management, fuzzy pattern matching, industrial performance, human workforce.

\section{Introduction}

Industrial performance, traditionally based on technical resources optimization, seems nowadays more "human resource centred". Indeed, as widely admitted, there is an increasing need for flexibility and reactivity in order to allow the companies to face the current global changes. In such a context, flexibility and reactivity naturally originate from the human factor, the other factors, more technically-oriented, being mastered for a long time.

Since McClelland has introduced the competencebased approach into the industrial area [5], the acquired/required competences paradigm seems to be one of the most accepted and used in operational competence management. According to this approach, also considered in this paper, two major levels of analysis characterize the competence lifecycle: i) the identification of competences and ii) their assessment.

At the top level, the result is generally a cartography of the critical competences required by the main processes of the company, which provide an overview on what is needed in terms of knowledge/ skills/abilities in order for the workers involved in the associated processes to be as efficient as possible. For that purpose, simple tools such as interviews and critical analysis methods are often used, with the result that the identification of the competences is usually a highly time consuming activity. In the literature, more formal/systematic methods are however described, for instance, amongst other, those centred on business processes or on techniques used in knowledge engineering [12].

The second level deals with the validation of the acquisition of a bundle of competences by a worker. This provides an instantaneous picture of the competence capital of the company, which reveals its strengths as well as its weaknesses for implementing the processes [4]. Such validation is generally based on a rough assessment of the knowledge/skills/abilities of the workers, a scale being often given, for instance from the value 0 (i.e. the worker does have the concerned competence) to 3 (for the higher level of the competence). Let us mention that, even seemingly simple, such (discrete) assessments may sometimes be far from a realistic analysis. Alternate methods have already been suggested in the literature, for instance based on the fuzzy logic theory, mainly focusing on the automation of the assessment. A fuzzy logic model has for instance been proposed in [15], aiming at providing an expert system allowing to assess competences through linguistics expressions (such as "poor", "acceptable" etc.) for predicting performance. In [6], the authors have introduced a fuzzy approach in order to identify the factors of performance, while the predictive model proposed in [16], based on clustering techniques, uses a similarity measure to compare each individual set of competences to a given profile of work situation, in order to predict the ability of the concerned worker to occupy the associated position. Within the same predictive allocation perspective, various models for describing fuzzy compatibility of skills for team selection [2] [11], or for personnel placement [10] [13] have been also proposed in the literature.

Predicting the ability of a worker to efficiently occupy a work position may in our opinion be difficult in an industrial context. Nevertheless, according to the assignment theory, as argued in [1], the allocation is optimal when the workers are allocated stepwise according to their skills, from the most competent to the least one. It appears then that an operational approach of assessing individual performance includes the comparison of a pattern, the set of required competences, to a "state of competence", the set of acquired competences. Therefore, we consider a fuzzy pattern matching process [7], as a promising tool of assessing competences.

This paper focuses on the improvement of the assistance to competences modelling by allowing to declare vague and imprecise assessments. After presenting the general context of the study, the classical competence management approach based on "ordinary" competences with precise values of assessment is 
presented, followed by the suggestion of a fuzzy logic framework for competence management.

\section{Context of the study}

The competence management as considered in this study is based on the continuous improvement principle, focusing particularly on the ISO 9000 norm, of which a major constraint is the necessity for the certified company to justify that each worker involved in a process has the appropriate background, in terms of knowledge/skills/abilities required to occupy the concerned position. In order words, considering that a process could be characterized by some work situations (activities), each of them may need some competences that a worker assigned is supposed to possess when assigned to this work situation (

Fig. 1). According to this continuous improvement point of view, we do not need to formalize an ontology of competence such as those proposed in the context of resource allocation. We will then focus on knowledge/skills/abilities without any mention to their respective concepts allowing to define a formal ontology of competence as described in [3] [14].

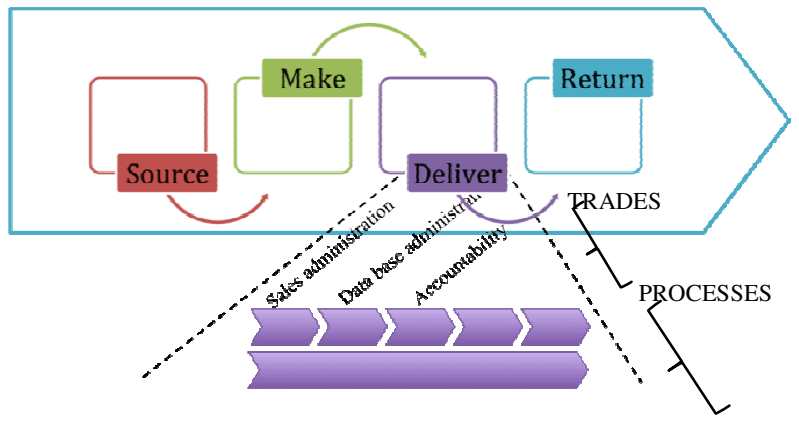

Fig. 1: Overview of the context.

Based on this approach, a competence management tool has been developed in ENIT and has been successfully implemented in several companies belonging to various industrial areas, but mainly the aeronautic one [8]. To provide the concerned companies with decision support indicators, we have used ordinary sets of required/acquired competences with precise measure of competence levels.

The main hypothesis in this case is that the company is able to clearly specify the competences required by each trade with its corresponding level. We have also supposed that human experts (sometimes the hierarchic headmaster of a workstation) can precisely assess the degree to which a competence is possessed by a worker. This framework is summarized in next section.

\section{Competence modelling with ordinary sets}

\subsection{Theoretical framework}

According to the quality management norm, in order to guarantee that the right worker is assigned to the right position within the value chain, it is necessary to define the sets of competences required by the industrial processes. Since these processes involve various trades, the required competences could also be directly linked to trades, which may be useful in practice (see Fig. 1).
Indeed, it can be time consuming for companies to formalize their processes, whereas all the trades occupied are already known.

Let $R_{e}=\left\{c_{j}\right\}_{j=1 \ldots n j}$ be the set of competences required by a trade and $\mathrm{A}_{\mathrm{c}}=\left\{\mathrm{c}_{\mathrm{k}}\right\}_{\mathrm{k}=1 \ldots \mathrm{nk}}$ the set representing a state of competences acquired by a worker. Theoretically, an elementary matching is successful when a given element of Ac also belongs to Re. But such analysis is so rough that it does not take into account the grade with which either a competence is required or acquired. Within each of the previous sets of competences, each ci, for $\mathrm{i}$ in $\left\{1, \ldots, \max \left(\mathrm{n}_{\mathrm{j}}, \mathrm{n}_{\mathrm{k}}\right)\right\}$, is then replaced by a value $\mathrm{w}_{\mathrm{i}}$, which is for instance equal to $0,1,2,3$ and represents the different degrees to which a competence is possessed.

\subsection{Illustration}

Based on the previous hypotheses, let us consider a set of trades, for instance "sales administrator", "database administrator", "accountant" etc. (Fig. 1). To characterize a trade, among other parameters, we have established the referential set of the required competences, each with a discrete required value according to the following scale: the value 0 is specified when the associated competence is not necessarily needed, the value 1 indicates that it is necessary to have some elementary notions, 2 for the worker should be autonomous for the associated competence and 3 when the worker should master it and may transmit it to someone else.

For illustration purpose, let us consider a worker occupying the "sales administrator" position. Given a bundle of critical competences necessary to occupy this work situation, two sets of measures are defined, referring to what is needed on one hand, and to what extend the worker's skills/knowledge/abilities comply with the requirements. These degrees of required and acquired competences are summarized in Table 1.

\begin{tabular}{|l|c|c|}
\hline Competence & $\begin{array}{c}\text { Required } \\
\text { level }\end{array}$ & $\begin{array}{c}\text { Acquired } \\
\text { level }\end{array}$ \\
\hline $\begin{array}{l}\text { Knowledge on the } \\
\text { production management } \\
\text { process (A) }\end{array}$ & 2 & 3 \\
\hline $\begin{array}{l}\text { Principles and tools of } \\
\text { stocks management (B) }\end{array}$ & 3 & 3 \\
\hline $\begin{array}{l}\text { Quality management } \\
\text { procedure (C) }\end{array}$ & 3 & 2 \\
\hline $\begin{array}{l}\text { Customer relationship } \\
\text { management (D) }\end{array}$ & 3 & 2 \\
\hline $\begin{array}{l}\text { Use of the main MS } \\
\text { office software (E) }\end{array}$ & 2 & 1 \\
\hline
\end{tabular}

Table 1: Example of competences assessment.

With these two sets of measures, it becomes easy to monitor the state of competences of a worker by comparing the levels of the pairs required/acquired competence, for instance, using a graphical tool such as a radar graph (see Fig. 2): the levels of the required 
competences are represented by a dark area and the competences possessed by the worker by a line.

It appears that the competence levels of this worker encompass the required ones of competences $\mathrm{A}$ and $\mathrm{B}$, which is not the case for the competences C, D and E. In other words, he is partially competent: thus, it would be difficult (based on the graph) to evaluate the whole adequacy of his background with the requirements set by its trade. However, such kind of specifications and assessments of competences has been satisfactory implemented in realistic industrial context [8]. Indeed, the concerned companies have defined some indicators such as "need of training" based on the gap between the required and the acquired levels of an elementary competence.

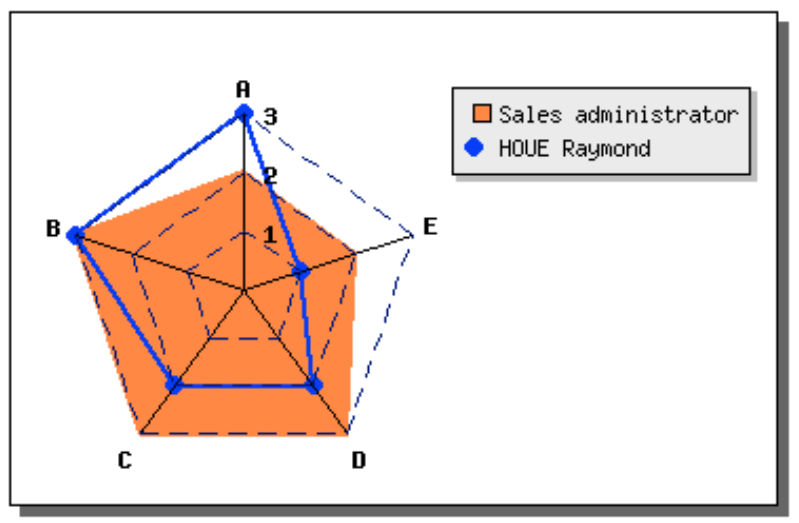

Fig. 2: Graphical analysis of competences.

However, while addressing a real problem, people do not necessarily have precise/numerical pieces of information. Indeed, the specification of required competences may be realistically vague, whereas the assessment of an acquired competence may be imprecise or even unknown. In other words, in a realistic context, the set of the required levels is an illbounded class of values and the set acquired levels an ill-known collection of values. The fuzzy logic theory provides a powerful framework for processing data allowing partial membership to a set, consistent with how a person would realistically make decisions.

\section{Fuzzy logic for competence management}

\subsection{Theoretical framework}

As stated previously, when specifying the requirements of a trade in a realistic context, the set of required degrees of mastering competences should be a fuzzy set. According to the fuzzy logic theory [16], such kind of set is characterized by a membership function (let say $\mu_{\mathrm{Re}}$ ), which allows to calculate the degree $d$ with which an element belongs to the set.

The assessment of $d$ may in practice be imprecise (since the bundle of acquired levels may be ill-known in a realistic context). Therefore, the grade of membership becomes also imprecise, and should be better represented by a fuzzy number in $[0,1]$. The set of the acquired levels could then be characterized by a possibility distribution $\pi_{\mathrm{Ac}}$. Hence, for calculating an elementary compatibility between a required and acquired competence (according to their respective levels), a function representing the degree of matching between the set of required competences and the possibility distribution of possessed competences is introduced. Such function estimates the possibility that the sets refer to the same value (according to the scale of assessment we will consider). In addition, for a deep analysis, it is common in fuzzy approaches to evaluate the certainty degree of each elementary matching. This corresponds in our case to the estimation of the degree of inclusion of the set of acquired levels into the set of the values compatible with the set of required levels.

Based on the fuzzy pattern matching framework firstly introduced in [7], in order to formalize the competences assessment analysis, the functions $\prod\left(\mathrm{R}_{\mathrm{e}} ; \mathrm{A}_{\mathrm{c}}\right)$ and $\mathrm{N}\left(\mathrm{R}_{\mathrm{e}} ; \mathrm{A}_{\mathrm{c}}\right)$ which represent respectively the so called possibility and necessity of matching between the required and acquired levels are introduced. Their formalizations are described in the following [7] [18]:

$$
\begin{gathered}
\Pi\left(R_{e} ; A_{c}\right)=\sup _{u \in U} \min \left(\mu_{R_{e}}(u), \pi_{A_{c}}(u)\right) \\
N\left(R_{e} ; A_{c}\right)=\operatorname{infmax}_{u \in U}\left(\mu_{R_{e}}(u), 1-\pi_{A_{c}}(u)\right)
\end{gathered}
$$

where

$$
\begin{aligned}
& \mu_{R_{e}} \text { is the membership function of } R_{e} \\
& \pi_{A_{c}} \text { is the distribution possibility of } A_{c} \\
& U \text { is the scale of assessment }
\end{aligned}
$$

For practical purpose, trapezoidal membership functions are generally used since they are usually sufficient for representing a smooth transition between subjective values without an important loss of precision. These trapezoidal functions allow to define fuzzy quantifiers when specifying the degree of requirements or while assessing the degree of mastering a competence by a worker (see

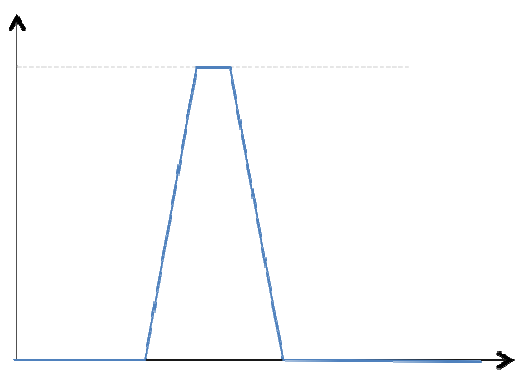

Fig. 3).

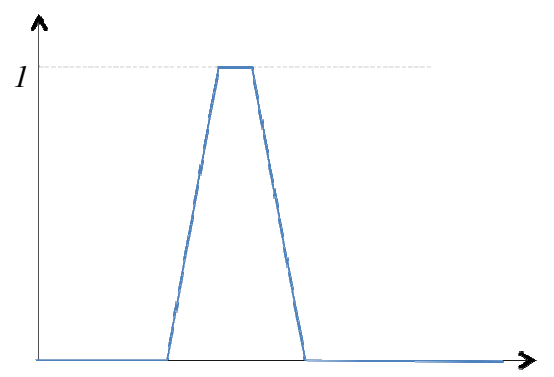

Fig. 3: Trapezoidal membership function. $U$ 
Based on this representation of membership function, it can then be checked that the possibility measure is the intersection of the two curves in Fig. 4 (straight lines representing the membership function the fuzzy set of required levels, whereas the dotted line stands for the distribution possibility of the acquired levels).

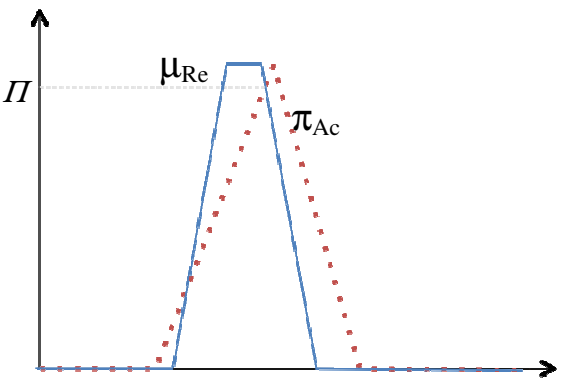

Fig. 4: Calculation of the possibility degree of matching between a fuzzy pattern and a possibility distribution.

In a same manner and according to the duality possibility/necessity (i.e. the necessity of an event is the impossibility of the opposite event), the necessity is graphically identified by the intersection of the membership function of $R_{e}$ and the opposite of the distribution possibility of $\mathrm{A}_{\mathrm{c}}$ (discontinuous lines in Fig. $5)$.

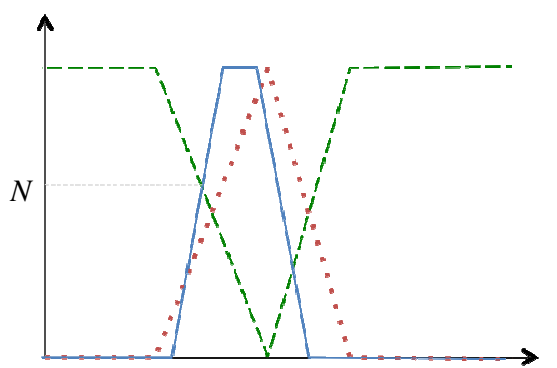

Fig. 5: Calculation of the necessity degree.

\subsection{Illustration of the fuzzy pattern matching}

\subsubsection{Presentation of the example}

This very simple and quite usual framework may lead to a highly intuitive representation of the competences, either required or acquired.

Let us firstly consider for instance the required competences. The issue is here to define a "pattern", i.e. a model to which real data should be compared (see [7]). In most of the implementations of the competence management software that we have performed, required competences were expressed by a crisp number, e.g. "2", or "3" (see Table 1). When a person was "allocated" to a trade, activity or process, a problem was then to decide whether persons having a higher competence were considered as adequate or not, which required to make a decision on each case. Using the fuzzy logic framework, the pattern becomes a fuzzy set, which allows to easily distinguish between a requirement on a precise competence level (" 2 ") and a "minimum" requirement "at least 2". This can be done in several ways: the continuous line of Fig. 6 represents for instance "at least 2" as an interval (2, 3, 4 and 5 fit this pattern).
Similarly, we can represent the linguistic label "at least 2" in a way which gives some flexibility around the threshold " 2 " (dotted line in Fig. 6), using a "real" fuzzy set. It is of course possible in that way to also model requirements like "less than 3", "around 4", etc., which lead to a much diversified power of expression than using the traditional crisp levels.

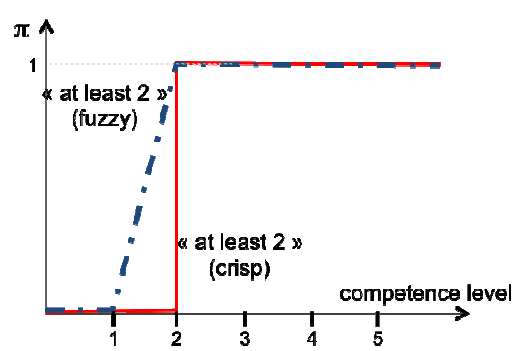

Fig. 6: Representation of the level "at least 2" as an interval.

The competences possessed by a person set a different problem, linked to the difficulty to precisely assess quite subjective characteristics of human actors. Therefore, we do not consider here fuzzy sets denoting patterns as in the previous step, but possibility distributions denoting an uncertainty on the real value of the level to which an actor possesses a competence.

As a first comment, the possibility to keep crisp values still exists, since a crisp value is a specific case of a trapezoidal fuzzy set. Possibility distributions can also be modelled by intervals, as in the crisp version of "at least 2" modelled in Fig. 6, or by fuzzy sets (denoting "around 4", etc.). Therefore, using a mix of crisp numbers, intervals and fuzzy sets does not set into question the possibility to use the formulae allowing to compute a possibility and a necessity degree. Nevertheless, the major interest is here the ability to model ignorance using possibility distributions: if the level of a given competence has not yet been assessed, it is nevertheless possible to compute a global ad equation between the competences possessed by a person and required by a process by using the usual way to represent ignorance in the possibility framework: $\Pi=1$ and $\mathrm{N}=0$.

The illustration of the competences assessment under the fuzzy pattern-matching framework as previously described is presented in the following. It is based on the illustrative example of Table 2.

\begin{tabular}{|c|c|c|}
\hline Competence & Required level & Acquired level \\
\hline A & 2 & "almost 3" \\
\hline B & "at least 2" & "around 3" \\
\hline C & 3 & "at most 3" \\
\hline D & "between 2 \& 3" & "around 3" \\
\hline E & "around 2" & "unknown" \\
\hline
\end{tabular}

Table 2: Example of competences assessment.

The required levels of competences $\mathrm{A}$ and $\mathrm{C}$ are supposed to be well known and defined by a singleton (respectively with the value 2 and 3 ) whereas 
competences B, D and E are imprecisely defined with linguistic quantifiers (respectively "at least 2", "between $2 \& 3$ " and "around 2").

In parallel, the levels of the possessed competences are also defined: we consider for our example that the competences A, B, C and D are imprecisely known (respectively through the linguistic quantifiers "almost 3", "around 3", "at most 3", "around 3". We consider furthermore that the level to which competence $\mathrm{E}$ is possessed is ignored.

All the competences are then represented with their respective membership functions: in the following figures, the singletons are represented with vertical bars which state for the precise associated values; the linguistic quantifiers are represented with their corresponding trapezoidal membership function and the ignorance evaluation with a horizontal bar at the level 1.

Within the graphs, an estimation of the possibility value of the matching is the intersection between the straight lines (membership function the fuzzy set related to the specification of a required level) and the dotted lines (membership of the possibility distribution of the evaluation of an acquired level). For the estimation of the necessity, the discontinuous lines are used in place of the dotted line.

\subsubsection{Analysis of the case study}

The calculation of the possibility and necessity values according to the matching evaluation of competence D is illustrated in Fig. 4 and Fig. 5 respectively. Those for the competences $\mathrm{A}, \mathrm{B}, \mathrm{C}$ and $\mathrm{E}$ are illustrated in the following.

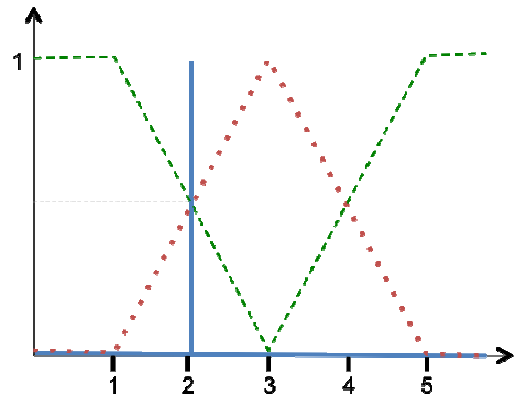

Fig. 7: Matching evaluation of competence A.

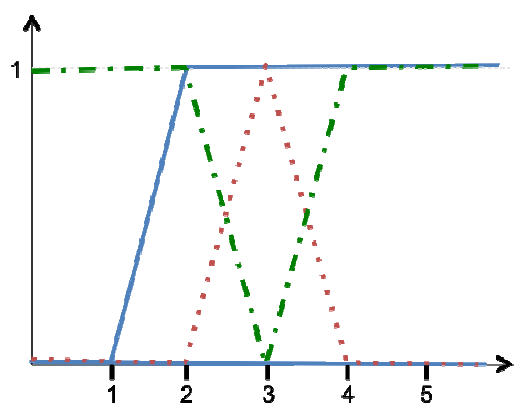

Fig. 8: Matching evaluation of competence B.

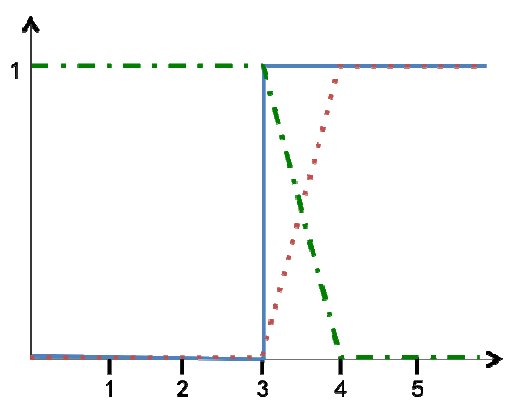

Fig. 9: Matching evaluation of competence C.

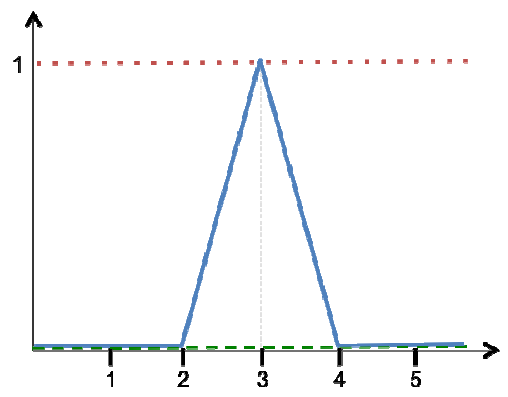

Fig. 10: Matching evaluation of competence E.

In order to provide a global matching of the worker background with the profile of his trade, we could use the aggregation framework suggested in [7] allowing to weight the various competences according to their importance, but the problem of setting up such weights is complex in an industrial context and has to be considered furthermore. As an example, we can use the minimum of the possibility (resp. necessity) degrees for providing a global evaluation (standing for a pessimistic assessment) or its maximum (optimistic attitude), or even the average value which is here quite meaningful in spite of its known limitations. According to the previous evaluations, the results are summarized in Table 3.

It can be seen that the fuzzy framework of course allows a discrimination giving a much more precise and robust assessment than the usual binary framework.

\begin{tabular}{|c|c|c|}
\hline Competence & Possibility & Necessity \\
\hline $\mathrm{A}$ & 0,5 & 0,5 \\
\hline $\mathrm{B}$ & 1 & 1 \\
\hline $\mathrm{C}$ & 1 & 1 \\
\hline $\mathrm{D}$ & 0,94 & 0,6 \\
\hline $\mathrm{E}$ & 1 & 0 \\
\hline $\begin{array}{c}\text { Global matching } \\
\text { (optimistic) }\end{array}$ & 1 & 1 \\
\hline $\begin{array}{c}\text { Global matching } \\
\text { (pessimistic) }\end{array}$ & 0,5 & 0 \\
\hline
\end{tabular}

Table 3: Example of competences assessment. 


\section{Conclusion}

Competence management is firstly based on the comparison between competences required by a trade, process, activity or role, and the competences possessed by an actor. The identification of the possible gaps between required and possessed competences then allows to launch corrective actions, mainly based on training.

This field is indeed a perfect domain for showing the interest to model data using fuzzy logic and possibility theory, since:

- the levels to which the competences are required may present some flexibility,

- the level to which a competence is possessed by a person may be imprecisely known, or even ignored.

In that context, we have shown that the problem of assessing the ad equation between a person and a role, trade, or activity is a pattern matching problem which may benefit from classical results in fuzzy logic. What is in our opinion remarkable is that, far from providing a quite artificial framework which adoption would be doubtful, the use of fuzzy logic allows to define a much more "natural" way of expression, which, by comparison, reveals the unexpected limitations of the classical crisp framework, however universally adopted.

The last point that we would like to address before testing this framework on real applications is the way information should be provided to the system, then how the results are given back to the user. Indeed, possibility and necessity degrees need to be processed for becoming interpretable by classical industrial users. This is the work which will be done now.

\section{References}

[1] J. Allen, R. van der Velden. Educational mismatches versus skill mismatches: effects on wages, job satisfaction, and on-the-job search. Oxford Economics Papers, 3, pages 434-452, 2001.

[2] A. Baykasoglu, T. Dereli and S. Das, "Project team selection using fuzzy optimization approach," Cybernetics and Systems, vol. 38, pp. 155-185, 2007.

[3] F. Belkadi, E. Bonjour, M. Dulmet, "Competency characterisation by means of work situation modelling", Computers in industry, vol. 58, n², pp. 164-178, 2007.

[4] X. Boucher, E. Bonjour, B. Grabot. Formalisation and use of competencies for industrial performance optimization: A survey. Computers in Industry, 58(2), pp. 98-117, 2007.
[5] M. Clelland. "Testing for competence rather for intelligence", American Psychologist, 28, pp. 1-14, 1973.

[6] M. Delgado, F. Cofré. A Fuzzy Model for Work Performance Assessment. EUSFLAT/LFA, 2005.

[7] D. Dubois, H. Prade, C. Testemale. Weighted fuzzy pattern matching. Fuzzy Sets and Systems. 28(3), 1988.

[8] B. Grabot, R. Houé, Operational Competence Management - Comparison of Industrial Frameworks, INCOM'09, Moscow, Russia, June 35, 2009.

[9] M. Harzallah, G. Berio, F. Vernadat. Analysis and modeling of Individual Competencies: Towards better Management of Human Resources. IEEE Transactions on Systems, Man. And Cybernetics Part A: Systems and Humans, 36(1), pp. 187-207, 2006.

[10] E. E. Karsak, "A fuzzy multiple objective programming approach for personnel selection," in Proceedings of the 2000 IEEE International Conference on Systems, Man, and Cybernetics, pp. 2007-2012, 2000.

[11] A. de Korvin, M.F. Shipley and R. Kleyle. "Utilizing fuzzy compatibility of skills sets for team selection in multi-phase projects". Journal of Engineering and Technology Management. Vol. 19, pp. 307-319, 2002.

[12] T. Ley, B. Kump, N.S. Lindstaedt, D. Albert, N.A.M. Maiden, S.V. Jones. Competence and Performance in Requirements Engineering: Bringing Learning to the Workplace. E. Tomadaki and P. Scott (Eds): Innovative Approaches for Learning Knowledge Sharing, EC-TEL 2006 Workshops Proceedings, ISSN1613-0073, pp. 148158, 2006.

[13] G. S. Liang and M. J. Wang, "Personnel placement in a fuzzy environment", Computers and Operations Research, vol. 19, pp. 107-121, 1992.

[14] G. Pépiot, N. Cheikhrouhou, J-M Fürbringer, R. Glardon, "A fuzzy approach for the evaluation of competences", International Journal of Production Economics, 112(1), pp. 336-353, 2008.

[15] S.A. Poveda, A.R. Fayek. Predicting and Evaluating Construction Trades Foremen Performance: Fuzzy Logic Approach. Journal of Construction Engineering and Management, vol. 135, Issue 9, pp. 920-929, September 2009.

[16] A. Suleman, F. Suleman. "Ranking by Competence using Fuzzy Approach". Quality \& Quantity. DOI 10.1007/s11135-010-9357-1.

[17] L.A. Zadeh. Fuzzy Sets, Inform. And Control, 8, pages 338-353, 1965.

[18] L.A. Zadeh. Fuzzy sets as a basis for theory of possibility, Fuzzy Sets and Systems, 1, pp. 3-8, 1978. 